\title{
INCOMPLETE BLOCK DESIGNS
}


This page is intentionally left blank 


\title{
INCOMPLETE BLOCK DESIGNS
}

\author{
Aloke Dey \\ Indian Statistical Institute, New Delhi, India
}
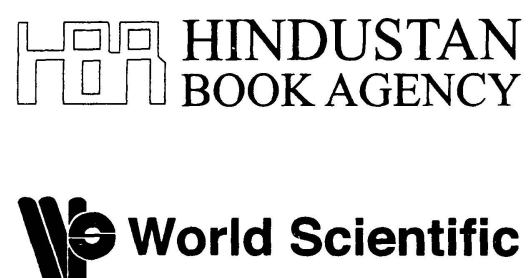

NEW JERSEY - LONDON - SINGAPORE - BEIJING - SHANGHAI - HONG KONG - TAIPEI - CHENNAI 


\section{Published by}

World Scientific Publishing Co. Pte. Ltd.

5 Toh Tuck Link, Singapore 596224

USA office: 27 Warren Street, Suite 401-402, Hackensack, NJ 07601

UK office: 57 Shelton Street, Covent Garden, London WC2H 9HE

\section{British Library Cataloguing-in-Publication Data}

A catalogue record for this book is available from the British Library.

\section{INCOMPLETE BLOCK DESIGNS}

Copyright $\odot 2010$ Hindustan Book Agency (HBA)

Authorized edition by World Scientific Publishing Co. Pte. Ltd. for exclusive distribution worldwide except India.

The distribution rights for print copies of the book for India remain with Hindustan Book Agency (HBA).

All rights reserved. This book, or parts thereof, may not be reproduced in any form or by any means, electronic or mechanical, including photocopying, recording or any information storage and retrieval system now known or to be invented, without written permission from the Publisher.

ISBN-13 978-981-4322-68-3

ISBN-10 981-4322-68-7

Printed in India, bookbinding made in Singapore. 


\section{Contents}

$\begin{array}{ll}\text { Preface } & \text { ix }\end{array}$

1 Introduction 1

1.1 Prologue . . . . . . . . . . . . . . . . . . 1

1.2 Outline of the Book . . . . . . . . . . . . 3

2 Analysis and Properties of Block Designs 6

2.1 Introduction . . . . . . . . . . . . . 6

2.2 Intra-block Analysis . . . . . . . . . . . . . . 7

2.3 Balancing in Block Designs . . . . . . . . . . 18

2.4 Recovery of Inter-block Information . . . . . . . . 26

2.5 Efficiency Factor . . . . . . . . . . . . . 38

2.6 Exercises . . . . . . . . . . . . . . . . 42

3 Balanced Designs $\quad 45$

3.1 Introduction . . . . . . . . . . . . . . . . . . 45

3.2 Some Properties of BIB Designs . . . . . . . . . . . . 45

3.3 Analysis of BIB Designs . . . . . . . . . . . . . . 56

3.4 Construction and Existence of BIB Designs . . . . . . 60

3.4.1 BIB Designs Through Finite Geometries . . . . . . 60

3.4.2 Method of Differences . . . . . . . . . . . 65

3.4.3 Some Other Constructions . . . . . . . . . . . . . 74

3.4.4 Existence of BIB Designs . . . . . . . . . . 76

3.5 Some Generalizations of BIB designs . . . . . . . . . . 77

3.6 Construction of Variance- and Efficiency-balanced Designs . . . . . . . . . . . . . . . . 80

3.7 Nested BIB Designs _ . . . . . . . . . . . . . . . 83

3.8 Exercises . . . . . . . . . . . . . . . 87 
4 Partially Balanced Designs 91

4.1 Introduction . . . . . . . . . . . . . . . 91

4.2 Introducing PBIB Designs . . . . . . . . . . . . . 92

4.3 The Algebra of Association Matrices . . . . . . . . . . . 94

4.4 PBIB Designs with Two Associate Classes . . . . . . . . . 97

4.4.1 Group-divisible Designs . . . . . . . . . . . . . 9 98

4.4 .2 Triangular Designs . . . . . . . . . . . . . . . 104

4.4.3 Latin Square Type Designs _. . . . . . . . . . . 108

4.4.4 PBIB Designs Based on Partial Geometries . . . . 110

4.4.5 Cyclic Designs with Two-associate Classes . . . . . 111

4.5 PBIB Designs with More Than Two Classes . . . . . . . . 114

4.5.1 Rectangular Designs . . . . . . . . . . . . . . . . 114

4.5.2 Generalized Right-angular Designs . . . . . . . . 115

4.5.3 Designs Based on Factorial Association Schemes . 116

4.5.4 Designs Based on Group-divisible Family of Schemes . . . . . . . . . . . . . 117

4.5.5 The $m$-dimensional Triangular Designs . . . . . . 117

4.5.6 Kronecker Product Designs . . . . . . . . . . . . 118

4.6 Analysis of PBIB Designs . . . . . . . . . . . . . . . 119

4.7 Lattice Designs . . . . . . . . . . . . . . . . . . . 122

4.8 Cyclic Designs . . . . . . . . . . . . . . . . . 125

4.9 Linked Block Designs . . . . . . . . . . . . . . . . . 129

4.10 C-Designs . . . . . . . . . . . . . . . 130

4.11 Alpha Designs . . . . . . . . . . . . . . . . 133

4.12 Exercises . . . . . . . . . . . . . . . 135

5 More Incomplete Block Designs 138

5.1 Introduction . . . . . . . . . . . . . . . 138

5.2 Designs for Factorial Experiments . . . . . . . . . . 139

5.3 Designs for Parallel Line Assays . . . . . . . . . . . . . . 148

5.3 .1 Introducing Bioassays . . . . . . . . . . . . . 148

5.3.2 Contrasts for Parallel Line Assays . . . . . . . . . 149

5.3.3 Block Designs for Parallel Line Assays . . . . . . . 154

5.4 Designs for Test-Control Comparisons . . . . . . . . . 165

5.5 Designs for Diallel Crosses . . . . . . . . . . . . . . . 171

5.6 Robust Incomplete Block Designs . . . . . . . . . . . . 177

5.6.1 Robustness Against an Outlier . . . . . . . . . 177

5.6.2 Robustness Against Missing Data . . . . . . . . . . . . . 179

5.6 .3 Trend-free Designs . . . . . . . . . . . . . . . . 183

5.7 Exercises . . . . . . . . . . . . . . . . 185 
6 Optimality Aspects of Block Designs 187

6.1 Introduction . . . . . . . . . . . . . . . . 187

6.2 Optimality Criteria . . . . . . . . . . . . . 188

6.3 Optimality of Proper Block Designs . . . . . . . . . . 197

6.3.1 Optimality of Symmetric Designs . . . . . . . . . 197

6.3.2 Optimality of Asymmetric Designs . . . . . . . . 200

6.3.3 D-optimality of Some Incomplete Block Designs . 208

6.4 Optimal Designs for Test-Control Comparisons . . . . . . 212

6.5 Optimal Designs for Parallel Line assays . . . . . . . . . . 219

6.6 Optimal Designs for Diallel Crosses . . . . . . . . . . . . 223

6.7 Exercises . . . . . . . . . . . . . . . . . 227

Appendix $\quad \mathbf{2 2 9}$

A.1 Some Results in Linear Algebra . . . . . . . . . . . . . 229

A.2 Some Aspects of Linear Models . . . . . . . . . . . . . 232

A.3 Finite Fields . . . . . . . . . . . . . . . . 236

A.4 Finite Geometries . . . . . . . . . . . . . . . . 240

$\begin{array}{ll}\text { References } & 243\end{array}$

$\begin{array}{ll}\text { Index } & \mathbf{2 7 7}\end{array}$ 
This page is intentionally left blank 


\section{Preface}

Block designs have applications in almost all areas of human investigation including agriculture, biology, engineering, medicine, physical and chemical sciences and industrial experimentation. The most primitive of the block designs is the randomized (complete) block design. However, in many practical situations, adoption of a complete block design is not appropriate and in some cases, not at all feasible. This fact prompted the development of various kinds of incomplete block designs, which in turn have been used extensively for experiments in a variety of fields. Moreover, these designs opened up many challenging problems in combinatorial mathematics. In view of the importance of block designs both from a theoretical and practical perspective, the author published a book Theory of Block Designs in 1986, which was well received in academic circles. However, the book went out of print around 1992. The author initially toyed with the idea of bringing out a second edition of the book, incorporating only minor additions/changes. While attempting to do so, however, it was realized that during the intervening period, the subject has grown considerably and the emphasis on certain topics has shifted. The author therefore decided to write the present book which, while retaining some of the flavor of the earlier book, is substantially different from it in both coverage and presentation.

The literature on incomplete block designs is vast and it is near impossible to cover each and every development in incomplete block designs in a single book of reasonable length. In this book, an attempt has been made to cover all the developments in this area which in the author's perception are the major ones. Since the classical incomplete block designs like the balanced incomplete block and partially balanced incomplete block designs are still found useful in several applications and newer applications of these, e.g., in visual cryptography, have been found, such designs have been covered at some length. Some of the more recent developments in incomplete block designs for special types of experiments, like biological assays and diallel crosses have also been discussed. Important results on the optimality aspects of various incom- 
plete block designs are also reviewed.

The book is organized into six chapters followed by an appendix. A brief description of the chapter contents appears in Chapter 1. The appendix covers some essentials on linear algebra, linear statistical models, finite fields and finite geometries. There are a large number of exercises at the end of Chapters 2-6 and there is a fairly exhaustive bibliography.

Throughout, results in matrix theory are used extensively and thus, a background in basic linear algebra and theory of matrices will be helpful in reading the book. Familiarity with the general area experimental designs and linear statistical models at an advanced undergraduate level is also assumed.

The book can be used in a variety of ways. The material in Chapter 2, the first four sections of Chapter 3 and Sections 4.1-4.4 and 4.6 of Chapter 4 can provide a solid foundation of the theory of incomplete block designs for a master's level course. The material in Sections 3.53.7, 4.7-4.11 and that in Chapters 5 and 6 may be used as a basis of a more advanced course. While the book is addressed to an audience whose primary interest is in the theory and applications of statistical design of experiments, portions of the book can also be used for a course in combinatorial designs for mathematicians. The material in Chapters 5 and 6 may be found useful for research students and consulting statisticians.

This work was supported by the Indian National Science Academy (INSA) under the Senior Scientist program of the Academy. The support is gratefully acknowledged. I sincerely thank Rahul Mukerjee for going through an early version of the manuscript and suggesting several changes for improvement. The manuscript was reviewed and commented upon by several referees and it is a pleasure to thank the reviewers for their comments. I would also like to thank the Editors of the TRIM Series for their constructive help. Rajendra Bhatia deserves special thanks for his dilligent and efficient handling of the project. Finally, I thank the Delhi Center of the Indian Statistical Institute for providing a conducive environment to carry out this work.

February, 2010

Aloke Dey

New Delhi 